\title{
Preludio al tema del modernismo en Puerto Rico
}

(CICLO GENERACIONAL: 1907 - 1921)

\section{I - ORÍGENES Y AFIRMACIÓN}

R L modernismo en Puerto Rico nace como una reacción esL tética frente a la fría y marmórea clasicidad parnasiana del ciclo generacional anterior (1880-1907). ${ }^{1}$ Surge de un lado, por influencia de los poetas modernistas hispanoamericanos: Rubén Darío (1867-1916), José Santos Chocano (18671934), Amado Nervo (1870-1919), Leopoldo Lugones (18691938), Julio Herrera Reissig (1875-1910), etc.; de la otra zona peninsular, por afinidades con los poetas españoles: Salvador Rueda, Juan Ramón Jiménez, Manuel y Antonio Machado, Francisco Villaespesa y Emilio Carrere; y del área norteamericana, se advierten marcadas simpatías hacia los poetas Edgar Allan Poe y Walt Whitman.

Los precursores de este movimiento lírico en la isla (y precursores, además, en Hispanoamérica), son los siguientes poetas: José de Diego (1866-1918), autor de Jovillos (Barcelona, 1916), libro de poemas premodernistas, publicados en España, entre 1887 y 1890, en las revistas: Madrid Cómico

1 Véase: Matos Bernier, Félix, Isla de Arte (San Juan, Puerto Rico, 1907), Caps. "Modernismo y Decadentismo", pp. 236 a 245, y "Musa Moderna", pp. 246 a 263; y además: Canales, Nemesio, Paliques (Puerto Rico, Editorial Universitaria, 1952), pp. 61 a 69. 
y La Semana Cómica, a la luz de Rubén Darío, príncipe de esta escuela poética. Cuando estudiaba en España José de Diego, dice el autor que:

\begin{abstract}
dirigia Madrid Cómico el ingeniosísimo Senesio Delgado, y la Semana Cómica, el bueno y excelente amigo José Fernández de la Reguera: alrededor de ellos, un estado mayor de escritores. Discípulo y compañero, el más joven $y$ humilde, fuí yo de aquella brillante y precursora generación literaria. ${ }^{2}$
\end{abstract}

En estas dos revistas, Madrid Cómico y La Semana Cómica, publicó José de Diego sus primeras producciones poéticas jocoserias, aunque en su mayoría de variaciones festivas y de puntas satíricas: poemas que aparecen recogidos posteriormente en su libro: Jovillos. Y precisa acentuar con tinta de recuerdo, que fueron estos poetas del Madrid Cómico y La Samana Cómica, los iniciadores del modernismo en la poesía española, entre ellos, José de Diego, que ya se iniciaba con paso firme y decidido en la matrícula de los nuevos módulos de las letras de entonces. Rubén Darío, corifeo del movimiento poético aludido, afirma el hecho en su obra: Cantos de Vida y Esperanza, de 1905, cuando el poeta nicaragüense nos dice:

en cuanto al verso libre moderno, ino es verdaderamente singular que en esta tierra de Quevedos, y de Góngoras, los únicos innovadores del instrumento lírico, los únicos libertadores del ritmo, hayan sido los poetas del Madrid Cómico y los libretistas del género chico ? ${ }^{3}$

En el orden del tiempo, José de Diego, fue el primer poeta modernista en Puerto Rico, cosa que ya habíamos probado en nuestra obra: La Poesía en Puerto Ríco, terminada en 1935, y publicada bajo el signo espiritual de la Universidad Nacional Autónoma de México, en el año de 1943.

2 De Diego, José, Jovillos (Barcelona, 1916), pp. 8 a 9. Y véase además: Rosa-Nieves, Cesáreo, La Poesia en Puerto Rico (México, D. F., 1943), pp. 217 a 220 .

3 Darío, Rubén, Cantos de Vida y Esperanza (Barcelona, s. f.), p. 10. 
Después de José de Diego, entre los precursores nuestros, va en turno cronológico: Luis Lloréns Torres (1878-1944), autor de un libro auroral: Al Pie de la Alhambra, publicado en Granada (España), en 1899. En este opúsculo poemático figuran las siguientes poesías, iluminadas por la nueva fórmula estilística: "Fragmento", "Soneto" y "Adiós".

Estos son nuestros madrugadores tanteos modernistas. Más adelante, en los preludios de esencia y presencia del nuevo estilo, nos hallamos con Arístides Moll Boscana, autor del libro: Mi Misa Rosa, de 1905; Jesús María Lago, autor de: El Canto de las Rosas, poema versolibrista de 1907, Cetro de Amor (1912), en donde el poeta utuadeño usa el eneasílabo como unidad melódica, y La Flota de los Sueños (1912), del mismo portalira: primer poema que usa la unidad melódica tetrasilábica en el parnaso isleño, adelantándose así, en este aspecto téenico, a Luis Lloréns Torres y su hermosa Canción de las Antillas (1913) ; y finalmente, Manuel Osvaldo García, autor de: Canto a España, publicado en 1911, poema estructurado en sextinas de catorce sílabas métricas.

Esta modalidad generacional de sello hispanoamericano, le debe su principal apogeo y acogedor desarrollo en el país, a la publicación de la Revista de las Antillas, fundada en el 1913, y que dirigía Luis Lloréns Torres en San Juan. Ya, con este palenque, en donde floreció la crítica de Nemesio Canales, Cristóbal Real, Miguel Guerra Mondragón, Luis Samalea Iglesia, y otros, el empuje se va acentuando hasta la influencia certera en los jóvenes alfareros del pensamiento poético de toda esa generación estética.

\section{II - ACLIMATACIÓN Y APORTES}

El versolibrismo simbolista se nacionaliza en nuestra poesía definitivamente con el precioso poema de enorme empeño: "La Canción de las Antillas" (1913), de Luis Lloréns Torres, aunque en el orden del tiempo, ya en 1910, el poeta de Collores había escrito su poesía: "Barcarolas" (o "Visión de la Barca"), de antecedentes modernistas, y su "Rapsodia Criolla", 
publicada en el Puerto Rico Ilustrado, del 14 de mayo de 1911, Año II, Núm. $63 .{ }^{4}$

La visita de varios poetas extranjeros a la isla, en el período generacional del modernismo (1907-1921); ayudó a la plasmación y enraizamiento de la nueva estética novecentista, tales líridas fueron: Salvador Rueda, José Santos Chocano y Francisco Villaespesa. ${ }^{5}$ La estada de José Santos Chocano en Puerto Rico (1913) prende un nuevo tema nativista, que había estado dormido en las liras isleñas : el tema de la patria. Chocano reinstala el asunto, le insufla nuevos entusiasmos, y recomienza a cantarse el paisaje, la historia y el deseo libertario, que con la aparición del Partido Unión de Puerto Rico (1904), José de Diego había orientado hacia la independencia. ${ }^{6}$

Como hemos señalado anteriormente, el modernismo en Puerto Rico es una modalidad estilística del movimiento modernista de Rubén Darío ( $\mathrm{y}$ otros poetas) en la América Hispana. De los corifeos líricos de Hispanoamérica, nuestros apolonidas recogieron las siguientes características generacionales: el versiculismo formal de origen norteamericano (Whitman) y de asimilación francesa (Verlaine), la ensoñación azul por el matiz y el color, la imaginativa sugerencia emocional, la nueva adjetivación preciosista, el orgullo por la creación de una metáfora doncella, musical y desnuda, la afición por la armonía de la sintaxis, el paisaje animista de sinestésicas connotaciones, la preocupación vital por la egolatría, y la vieja

4 Véase: Revista de las Antillas, Año I, junio de 1913, Núm. 4, pp. 85 a 95. Consúltese además nuestro ensayo: "Cinco Generaciones Estéticas en la Poesía Puettorriqueña", en Estudios Americanos, (Sevilla, España), Vol. XI, Núm. 54, Marzo 1956, pp. 1 a 211.

5 Rubén Darío visitó a Puerto Rico en un tiempo tan breve, que solamente una minoria de intelectuales de San Juan tuvo la bella oportunidad de cambiar impresiones literarias con él.

6 El tema de la libertad de la patria aparece en los siguientes poemarios de José De Diego: Pomarrosas (Barcelona, 1904), Cantos de Rebeldía (Barcelona, 1916), y Cantos de Pitirre (San Juan, 1950). El poeta de Aguadilla tomó cono símbolo de la libertad de su pueblo, el pitirre.

El libro de José Santos Chocano se publica en San Juan, P. R. en 1914, bajo el título: Puerto Rico Lírico y Otros Poemas, con un prólogo de Luis Lloréns Torres. 
fórmula alejandrina del arte por el arte, de prolongación romántica.

\title{
III - CONCLUSIÓN
}

Nuestra modesta aportación a la escuela modernista hispanoamericana puede sintetizarse en dos zonas presidentes: de un lado el aspecto temático, en donde la lírica puertorriqueña ensaya el tema de la poesía negra afroantillana (Luis Palés Matos y Fortunato Vizcarrondo) ; la jibaridad poética elevada a diapasón culto (Luis Lloréns Torres, Virgilio Dávila, el Padre Juan Rivera Viera, etc.) ; la emoción colorista del paisaje tropical, con un fondo de tristeza violácea muy puertorriqueño, visible en casi todos nuestros poetas (Evaristo Ribera Chevremont, José A. Balseiro, Joaquín Monteagudo Rodríguez, Antonio Nicolás Blanco, Luis Antonio Miranda, Carlos N. Carreras, Jesús María Lago, José de Jesús Esteves, José P. H. Hernández, etc.) ; y el tema de la libertad de la patria: (José de Diego, Luis Lloréns Torres, etc.). En el aspecto de la arquitectura del verso, se ensayaron casi todas las modalidades técnicas usadas por Rubén Darío en su poesía, amén del uso del hexámetro latino, practicado aquí con bastante buen éxito por el poeta Arturo Gómez Costa, y un intento de creación, por Luis Lloréns Torres, de dos nuevos endecasílabos: uno con acentos en 3a. y 7a., y otro con acentos en 5a. y 8a. Lo demás pertenece al versolibrismo rubendariano, cuya implantación en la isla hemos explicado anteriormente. ${ }^{7}$

\author{
Cesáreo Rosa-Nieves \\ Universidad de Puerto Rico, \\ Río Piedras, Puerto Rico
}

\footnotetext{
7 La invención de Luis Lloréns Torres fue el endecasílabo de 5ta. y 8va., pues el de 3ra. y $7 \mathrm{ma}$. había sido ensayado por el peruano Manuel González Prada con anterioridad. Véase Lloréns Torres, Luis, Sonetos Sinfónico. (San Juan, P. R., 1914), pp. 9-21.
} 
